\title{
Antimicrobial potential of bacteriocins in poultry and swine production
}

\author{
Amel Ben Lagha', Bruno Haas ${ }^{1}$, Marcelo Gottschalk ${ }^{2,3}$ and Daniel Grenier ${ }^{1,3^{*}}$
}

\begin{abstract}
The routine use of antibiotics in agriculture has contributed to an increase in drug-resistant bacterial pathogens in animals that can potentially be transmitted to humans. In 2000, the World Health Organization identified resistance to antibiotics as one of the most significant global threats to public health and recommended that the use of antibiotics as additives in animal feed be phased out or terminated, particularly those used to treat human infections. Research is currently being carried out to identify alternative antimicrobial compounds for use in animal production. A number of studies, mostly in vitro, have provided evidence indicating that bacteriocins, which are antimicrobial peptides of bacterial origin, may be promising alternatives to conventional antibiotics in poultry and swine production. This review provides an update on bacteriocins and their potential for use in the poultry and swine industries.
\end{abstract}

\section{Table of Contents}

1 Antibiotic use and resistance in poultry and swine production

2 Bacteriocins

2.1 Generalities

2.2 Classification

2.2.1 Class I (lantibiotics)

2.2.2 Class II (non-lantibiotics or unmodified peptides)

2.2.3 Class III (high molecular mass peptides)

2.2.4 Class IV (circular peptides)

2.3 General uses of bacteriocins

3 Bacteriocins in poultry and swine production

3.1 Poultry pathogens

3.2 Swine pathogens

3.3 Foodborne pathogens

4. Conclusions

${ }^{*}$ Correspondence: Daniel.Grenier@greb.ulaval.ca

1 Groupe de Recherche en Écologie Buccale (GREB), Faculté de médecine

dentaire, Université Laval, Quebec City, QC, Canada

Full list of author information is available at the end of the article

\section{Antibiotic use and resistance in poultry and swine production}

Antibiotics are used in animal production for three main purposes: (1) as therapeutics to treat established infections, (2) as prophylactics/metaphylactics to prevent the development of bacterial diseases in clinically healthy animals, and (3) as growth promoters to improve feed conversion and body-weight gain. Despite the adoption of regulations banning the use of antibiotics for disease prevention and growth promotion by many countries, antibiotic-supplemented feeds can still be purchased without a veterinary prescription in a number of major animal-producing countries, including the United States, Canada, China, and Australia [1,2]. These practices often expose bacteria to sublethal doses of antibiotics and consequently may favor the emergence of drug-resistant bacterial strains. It should be pointed out that a correctly provided therapeutic treatment also exerts antibiotic selective pressure that may promote antibiotic resistance.

Approximately $80 \%$ of all antibiotics sold or distributed in the United States in 2012 were for animal agriculture [3]. Sales of medically important antibiotics for use in food-producing animals are dominated by tetracyclines (67\%), followed by penicillins (11\%), macrolides (7\%), sulfonamides (6\%), aminoglycosides (8\%), lincosamides $(2 \%)$, and cephalosporins $(<1 \%)$ [3]. A recent study from 
Germany revealed that tetracyclines were the most common antibiotics used in pigs, followed by beta-lactams and trimethoprim-sulfonamides [4]. From 2011 to 2014, a similar distribution in various food-producing animals, including pigs, poultry, and cattle, was observed in most European countries [5]. Antibiotics specifically used by the poultry and swine industries make up approximately $67 \%$ of global animal health antimicrobial needs [6].

While antibiotics are required to treat infections and maintain animal health, they are not essential for promoting animal growth. The use of antibiotics as antimicrobial growth promoters (AGP) is based on observations reported more than 50 years ago indicating that the addition of sub-therapeutic amounts of antibiotics to poultry and swine feeds had a significant growth-promoting effect on the animals, increasing weight gain and meat production [7]. Antibiotics benefit animal health at least in part by modulating the immune system and modifying the microflora of the gastrointestinal tract resulting in a reduction of the total bacterial load and suppression of pathogens [8]. One of the major benefits of AGP may be maintaining animal health in older facilities, where hygiene management is less efficient. However, the growth response to AGP appears to be much less important when animal nutrition, hygiene practices, as well as genetic potential and health status of animals are optimal. Indeed, recent studies (post-2000) have shown that productivity gains from AGP are lower than what was reported in earlier studies [7, 9, 10]. More specifically, Miller et al. [9] reported that the use of AGP in pork production increased the average daily weight by $0.5 \%$ and feed efficiency by $1.1 \%$; that is much less that previously reported in the 1980s [10]. With respect to the broiler chicken industry in Denmark, the mortality rate, the average weight gain, and productivity from 1995 to 1999 were not affected by the ban of AGP [11]. In general, the current scientific evidence tends to suggest that it is possible for the swine and poultry industries with optimized production systems to maintain efficient production at cost-effective without using AGP [12].

Bacteria may become resistant to antibiotics through three major mechanisms: physiological adaptation, mutations, and transfer of resistance genes [13]. The extensive use of antibiotics in food-producing animals has contributed to an increase in drug-resistant animal pathogens that can potentially be transmitted to humans and negatively impact human health [14]. For instance, in the swine industry, most enterotoxigenic Escherichia coli strains are resistant to tetracyclines, aminoglycosides, trimethoprim-sulphonamides, and ampicillin [15]. The emergence of resistance to fluoroquinolones and colistin has also been reported [16, 17]. Moreover, Streptococcus suis, a swine pathogen and important zoonotic agent, is highly resistant to macrolides such as erythromycin, tetracyclines and, to a lesser extent, penicillin [18, 19]. Wang et al. recently discovered the $c f r$ gene, which confers to $S$. suis a multi-resistance to five different classes of antibiotics (phenicols, oxazolidinones, lincosamides, pleuromutilins, and streptogramin A) [20]. Regarding the poultry industry, E. coli strains resistant to multiple antibiotics (tetracycline, ampicillin, streptomycin) are frequently isolated [21, 22]. Resistance genes have also been identified in Salmonella serovars, Enterococcus spp., and Clostridium perfringens recovered from feces and ceca of broiler chickens [23].

The transmission of resistant bacteria from animals to humans may occur through direct contact with animals or through the consumption of or contact with uncooked contaminated meat. Indirect transmission through the environmental pathways is also possible [24]. The transmission of resistance genes into human bacterial pathogens by horizontal gene transfer is also to consider although it remains relatively difficult to prove. It has been suggested that the increased bacterial resistance to certain antibiotics in both animals and humans is correlated with their addition to animal feed and their use in veterinary medicine. A typical example is fluoroquinolone resistance in Campylobacter species which has been associated with the use of these antibacterial agents in poultry [25]. In 2000, the World Health Organization (WHO) identified resistance to antimicrobial agents as one of the most significant global threats to public health and recommended that the use of antibiotics as additives in animal feeds should be phased out or terminated, particularly those used to treat human infections [26]. In order to attenuate this increase in antibacterial resistance, countries of the European Union banned the use of AGP in livestock in 2006. In the United States, progress in restricting AGP use in animal production has been relatively modest despite the fact that the Food and Drug Administration (FDA) adopted a voluntary policy in December 2013 recommending that producers stop the routine use of antibiotics and consult veterinarians before using them [27]. Pressure from consumers is likely to encourage the food-producing animal industry to eliminate the use of antibiotics in animal feeds. Few studies investigated whether reduction of antibiotic selection pressures through a ban is associated with a reduction in the occurrence of resistant bacteria. On the one hand, the decision to ban AGP in Denmark in 1986 resulted in a decrease in antibiotic-resistant bacteria in animals, food, and humans $[28,29]$. On the other hand, in the USA, the ban of fluoroquinolones in chicken did not result in a declined incidence of fluoroquinolone-resistant Campylobacter strains [30]. However, it is of interest to mention that an increase in the use of antibiotics for a therapeutic 
purpose has been observed since the ban of AGP by the European Union countries, likely because of the producers' expectations regarding performance enhancement and disease prevention [31].

Whenever and whatever antibiotics are used in animal production, it creates a selective pressure for the emergence of antibiotic-resistant bacteria. For this reason, there is a need for novel antibacterial compounds that can be used in animal production and for which bacteria do not easily develop resistance that may potentially be transmissible to human pathogens. In this regard, bacteriocins, which were discovered in 1925 by Gratia [32], are of great interest for controlling both animal and foodborne pathogens. This review provides an update on bacteriocins and their potential for use in the swine and poultry industries.

\section{Bacteriocins}

\subsection{Generalities}

Bacteriocins are ribosomally synthesized bactericidal or bacteriostatic peptides produced by certain bacteria. Although Gram-negative bacteria can produce bacteriocins, the vast majority of bacteriocins characterized so far are produced by Gram-positive bacteria [33]. BACTIBASE, an open-access database on bacteriocins, contains 177 bacteriocin sequences, of which 156 are from Gram positive bacteria and 18 are from Gram negative bacteria [33]. According to this database, the peptide length for bacteriocins produced by Gram positive bacteria ranges from 20 to 60 amino acid residues while bacteriocins from Gram negative bacteria have a wider range of lengths with the longest having 688 amino acid residues. The widespread occurrence of bacteriocins among bacterial species isolated from complex microbial communities suggests that these bacterial products may play a regulatory role in terms of population dynamics within bacterial ecosystems.

Bacteriocin production involves several genes implicated in the modification of amino acids, the export and regulation of the bacteriocin, as well as self-immunity [34]. These genes may be located on the chromosome or on a plasmid [34]. The producing bacteria usually synthesize self-immunity proteins that protect them from being killed by their own bacteriocins [35]. The immunity proteins protect cells by scavenging bacteriocins or by antagonistic competition for the bacteriocin receptor. While many bacteriocins have a narrow spectrum of activity, inhibiting the growth of similar or closely related bacterial species, others display antimicrobial activity against a broad array of genera [34]. Usually, the activity spectrum exerted by bacteriocins of Gram negative bacteria is narrower than those produced by Gram positive bacteria.
Several bacteriocins have been shown to act in synergy with conventional antibiotics [36, 37], thus allowing to reduce bactericidal concentrations and decrease their undesirable side-effects. Interestingly, some bacteriocins produced by Gram positive bacteria have been found to be active against viruses [38, 39]. Bacteriocins, depending on their primary structure, may exert antibacterial activity through different modes of action on susceptible bacteria. Some act on the bacterial cell envelope causing cell lysis, while others are active once inside the cells, affecting gene expression and protein production [40].

As observed with the antibiotics, bacteria can develop resistance against bacteriocins principally through modifications of their cell envelope such as alterations in charge and thickness [41-44]. However, since bacteriocins have not been extensively tested in clinical setting yet, this aspect has been poorly investigated.

Bacteriocins possess a wide range of sizes, structures, modes of action, activity spectra, and target cell receptors. The classification of bacteriocins undergoes continuous modifications because of new developments regarding their structures and modes of action. According to the classification proposed by Heng and Tagg [45], they are divided into four classes. This classification may be considered universal since it includes bacteriocins from both Gram-positive and Gram-negative bacteria. The four classes include (I) lantibiotics, (II) non-lantibiotics or unmodified peptides, (III) high molecular mass peptides, and (IV) circular peptides (Table 1).

\subsection{Classification}

\subsubsection{Class I (lantibiotics)}

Class I bacteriocins, or lantibiotics, are low molecular mass peptides $(2-5 \mathrm{kDa})$ produced by Gram-positive bacteria [46]. They are thermostable and resistant to extreme $\mathrm{pHs}$ and certain proteases. The main feature that differentiates them from other bacteriocins is the presence of atypical post-translationally, enzymatically modified amino acids such as lanthionine, methyllanthionine, dehydroalanine, and dehydrobutyrine [46]. The most widely recognized representative of this class is nisin, which is produced by Lactococcus lactis subst. lactis. Lantibiotics have a dual mode of action against susceptible bacteria [40]. They can bind to lipid II, the major transporter of peptidoglycan subunits, interfering with cell wall synthesis. In addition, they can also use lipid II as a docking molecule, leading to pore formation and cell death. Because of this mode of action, high resistant mutants to lantibiotics cannot develop. Lantibiotics can be sub-divided into three categories based on their structures and functional properties: linear (type a), globular (type b), and multi-component (type c). The lantibiotic biosynthesis machinery is encoded by gene clusters that 
Table 1 Classification of bacteriocins and their major features

\begin{tabular}{|c|c|c|c|}
\hline Class & Subclass & Example & Features \\
\hline I (lantibiotic) & $\begin{array}{l}\text { la (linear) } \\
\text { lb (globular) } \\
\text { Ic (multi-components) }\end{array}$ & $\begin{array}{l}\text { Nisin A } \\
\text { Suicin } 3908 \\
\text { Lacticin } 3147\end{array}$ & $\begin{array}{l}\text { - MW }<5 \text { kDa } \\
\text { - Linear peptide } \\
\text { - Presence of modified amino acids (lanthionine, methylanthio- } \\
\text { nine) } \\
\text { - Heat-stable }\end{array}$ \\
\hline II (non-lantibiotic) & $\begin{array}{l}\text { Ila (pediocin-like) } \\
\text { Ilb (miscellaneous) } \\
\text { Ilc (multi-components) }\end{array}$ & $\begin{array}{l}\text { Pediocin PA-1 } \\
\text { Aureocin A53 } \\
\text { Lactococcin G }\end{array}$ & $\begin{array}{l}\text { - MW }<10 \mathrm{kDa} \\
\text { - Linear peptide } \\
\text { - Absence of modified amino acids } \\
\text { - Heat-stable }\end{array}$ \\
\hline$\| 1$ & $\begin{array}{l}\text { Illa (bacteriolytic) } \\
\text { IIlb (non-lytic) }\end{array}$ & $\begin{array}{l}\text { Lysostaphin } \\
\text { Helveticin J }\end{array}$ & $\begin{array}{l}\cdot \mathrm{MW}>25 \mathrm{kDa} \\
\text { - Linear peptide } \\
\text { - Heat-sensitive }\end{array}$ \\
\hline IV & None & Enterocin AS-48 & $\begin{array}{l}\text { - } M W<8 \text { kDa } \\
\text { - Cyclic peptide }\end{array}$ \\
\hline
\end{tabular}

a This subclass includes bacteriocins with distinct features.

typically include a structural gene for a pre-lantibiotic peptide as well as genes required for the modification of amino acids, export, regulation, and self-immunity [46]. More specifically, the structural gene encodes a prepeptide containing a leader sequence at the $\mathrm{N}$-terminus, which is eventually cleaved, and a propeptide at the C-terminus in which many or all of the serine and threonine residues are modified.

\subsubsection{Class II (non-lantibiotics or unmodified peptides)}

Class II bacteriocins (non-lantibiotics) are thermostable, small $(<10 \mathrm{kDa})$ peptides with an amphiphilic helical structure that do not contain modified amino acid residues [47]. Generally, the class II bacteriocins target the lipid II as the lantibiotics or bind to the pore-forming receptor mannose phosphotransferase system [40]. This class is divided into three sub-classes (IIa, IIb, IIc). Class IIa bacteriocins (pediocin-like) include peptides that have the YGNGVXC consensus sequence at the N-terminus and that display a strong inhibitory activity against the food pathogen Listeria monocytogenes [47]. Class IIb bacteriocins contain heterogeneous linear peptides unrelated to pediocin. Lastly, class IIc bacteriocins comprise bacteriocins that require two unmodified peptides in about equal quantities to exert their antibacterial activity. When tested individually, these bacteriocins display low if any activity. Each peptide pair, that differs in their amino acid sequence, is encoded by two genes located in the same operon.

\subsubsection{Class III (high molecular mass peptides)}

Class III bacteriocins, which have been poorly studied, include large, thermolabile peptides $(>10 \mathrm{kDa})$ and are divided into two sub-classes: bacteriolytic (IIIa) and nonlytic peptides (IIIb) [47]. The mode of action of bacteriolytic peptides is different from that of other bacteriocins as they catalyze peptidoglycan hydrolysis resulting in lysis and death of the target cells. Non-lytic peptides, as their name implies, do not cause cell lysis. Depending on the bacteriocin, different mechanisms may be used such as membrane leakage of small molecules, inhibition of sugar uptake, and inhibition of DNA synthesis [48].

\subsubsection{Class IV (circular peptides)}

Lastly, class IV bacteriocins are post-translationally modified circular peptides that possess a covalent bond between the $\mathrm{N}$ - and $\mathrm{C}$-terminals. The circular bacteriocins that have been identified so far are all produced by Gram positive bacteria [49]. The circular bacteriocins possess a wide activity spectrum and exhibit high resistance to heat, extreme pHs, and proteolytic enzymes [49]. These bacteriocins generally exert their antibacterial action by disruption of the membrane integrity [50].

\subsection{General uses of bacteriocins}

Most studies on bacteriocins produced by food-grade lactic acid bacteria have investigated the food preservation potential of the bacteriocins because of their impressive in vitro and in situ efficacy against foodborne pathogens [51, 52]. In this context, several strategies have been proposed: (1) the addition of a purified or semipurified bacteriocin as a food preservative, (2) the use of a product previously fermented with a bacteriocinproducing bacterium as an ingredient/supplement in the food preparation process, and (3) the inoculation of food with the bacteriocin-producing strain.

Nisin A, which is produced by L. lactis subsp. lactis, is the most studied bacteriocin and was approved in 1988 as a generally recognized as safe (GRAS) by the FDA due to its low toxicity in humans [53]. It is a lantibiotic (type a; 34 amino acid residues) that is commercially used as a food preservative (E234, Nisaplin ${ }^{\circledR}$ ), especially in dairy 
products, in more than 50 countries, including the United States and several member countries of the European Union [54]. Although the main application of nisin is as a natural food bio-preservative, its recognized potential has been extended to the biomedical field, including the prevention/treatment of infectious diseases [55]. A nisinbased formulation (Wipe Out ${ }^{\circledR}$ Dairy Wipes; Immucell, USA) has also been shown to be effective for treating mastitis caused by Staphylococcus aureus, Streptococcus uberis, and Streptococcus dysgalactiae in lactating dairy cows $[56,57]$.

Given the increasing concern about the acquisition of antibiotic resistance by pathogens, bacteriocins are being given serious consideration as a viable strategy to replace conventional antibiotics or to potentiate their effects against pathogens [58]. Unlike antibiotics, most bacteriocins are relatively specific and can thus be used to target particular pathogenic or non-beneficial bacteria without affecting the indigenous microflora. New bacteriocins with promising in vitro antimicrobial profiles and in vivo effectiveness are currently being identified. The use of bacteriocins as alternatives or adjuncts to help alleviate antibiotic overuse and resistance has become a very real possibility. In vivo trials with animal models have shown that lantibiotics can successfully prevent or treat infections. For example, nisin F (L. lactis) prevents respiratory infections by $S$. aureus in a rat model [59], while mersacidin, a lantibiotic produced by Bacillus spp., can eradicate MRSA colonization in a mouse rhinitis model [60]. Lastly, lacticin (L. lactis) has been reported to successfully control the systemic spread of $S$. aureus in a mouse model [61]. Interestingly, bacteriocins are considered to be natural antimicrobials that are nontoxic for eukaryotic cells [62].

Additional properties have recently been associated with lantibiotics [58]. Chopra et al. [63] reported that a bacteriocin produced by Bacillus sonorensis can prevent adherence and biofilm formation by food spoilage bacteria. Several bacteriocins produced by Gram-positive bacteria have also been reported to possess anti-cancer properties [64].

\section{Bacteriocins in poultry and swine production}

\subsection{Poultry pathogens}

The poultry industry has become an important economic activity in many countries. The impact of diseases on poultry production is one of the major factors that limit the success of this industry [65]. The high incidence of bacterial infections combined with the increase in drug-resistant pathogens is pushing the poultry industry to develop novel antimicrobial strategies. The potential of using bacteriocins to inhibit bacterial pathogens that affect the poultry industry and cause important economic losses is currently being investigated by several groups. Most studies on this aspect have focused on $C$. perfringens and $E$. coli, two major pathogens in the poultry industry.

The Gram-positive spore-forming anaerobic bacterium $C$. perfringens, which colonizes the intestinal tract of chickens, is the causative agent of necrotic enteritis [66]. Given the production losses and animal mortality, C. perfringens is considered to be the main disease of concern for poultry producers worldwide [66]. Since this bacterial species is also a foodborne pathogen associated with poultry, antimicrobial agents that can inhibit or kill it may also contribute to preventing potential food safety problems. Timbermont et al. [67] purified and characterized a bacteriocin (perfrin) produced by a strain of $C$. perfringens isolated from a chicken with necrotic enteritis. The $11.5-\mathrm{kDa}$ bacteriocin is effective against other strains of type A C. perfringens. Given that the bacteriocin is only produced by strains expressing the NetB toxin and that the bacteriocin-producing strain is not susceptible to perfrin, the authors suggested that the bacteriocin likely contributes to the pathogenesis of necrotic enteritis by enabling the producing strain to outcompete other $C$. perfringens strains in the gut rather than by acting as a peptide with therapeutic potential [67]. Han et al. [68] conducted a search for bacteria with antagonistic activity against $C$. perfringens and isolated six Enterococcus faecalis strains from pig feces that inhibit C. perfringens. Although they did not purify the bacteriocin-like inhibitory substances, they suggested that these bacteria or their antibacterial compounds may be useful alternatives to antibiotics in the poultry industry. Several Bacillus spp., including Bacillus cereus [69], Bacillus subtilis [70, 71], Bacillus pumilus [72], and Bacillus licheniformis [72] have been reported to exert antagonism against $C$. perfringens through the production of bacteriocins. Jayaraman et al. [73] investigated the effect of a bacteriocin-producing B. subtilis strain, isolated from healthy chicken gut and used as a dietary supplement, on intestinal health and gut integrity in broiler chickens infected with $C$. perfringens. It was shown that supplementation with $B$. subtilis reduces intestinal lesion score and significantly lowers the intestinal $C$. perfringens counts compared with the infected control group [73]. Grilli et al. [74] reported that pediocin A, a bacteriocin produced by Pediococcus pentosaceus, was highly active against $C$. perfringens in an in vitro assay. They also showed that a partially purified fraction of pediocin A, alone or in association with the producer strain, significantly improves the growth performance of broiler chickens challenged with $C$. perfringens [73]. A recent study by Udompijitkul et al. [75] showed that nisin exerts strong antimicrobial activity against $C$. perfringens in vitro. In addition, 
Jozefiak et al. [76] reported that dietarynisin significantly and dose-dependently increases feed conversion by and the growth performance of broiler chickens. Like salinomycin, a widely used ionophore coccidiostat, nisin exerts a modulating effect on the microbiota of the gastrointestinal tract by decreasing counts of Bacteroides and Enterobacteriaceae [76]. It thus represents an effective dietary supplement for broiler chickens. Similar effects were reported for other bacteriocins, including diversion produced by Carnobacterium divergens [77] and albusin B produced by Ruminococcus albus [78].

Escherichia coli is a Gram-negative bacterium that is a normal member of the gastrointestinal microflora of poultry. Some strains can, however, cause severe diseases, commonly referred to as colibacillosis in chickens [79]. Systemic infections develop when large numbers of avian pathogenic E. coli gain access to the bloodstream from the respiratory or intestinal tract, especially if the host is stressed or their immune system is compromised [79]. Torshizi et al. [80] screened lactic acid bacteria isolated from chicken intestinal samples and found two isolates (Lactobacillus fermentum and Lactobacillus rhamnosus) with the capacity to inhibit the growth of $E$. coli in vitro. The nature of the inhibitory substances produced by these isolates suggests that they may be bacteriocins. Ogunbanwo et al. [81] investigated the potential therapeutic efficacy of bacteriocin and bacteriocin-producing Lactobacillus plantarum strain in an experimental E. coli infection of broiler chickens. They found that when chickens infected with $E$. coli are treated with bacteriocin alone or bacteriocin-producing L. plantarum, their health status is comparable to that of uninfected control chickens [81].

\subsection{Swine pathogens}

The swine industry has experienced remarkable growth over the past 20 years. In addition to be linked to the increased demand, this trend is also related to the industrialization of processes, mass rearing, and increased efficiency of slaughterhouses, which have reduced production costs. In 2012, the swine industry dominated the world meat market with $36.3 \%$ of total production [82]. Between 2010 and 2012, the industry produced nearly 100 million tons of meat per year on average, half in China [82]. Increasing the capacity of farms and slaughterhouses has concentrated a large number of animals in confined spaces, making it harder to control bacterial and viral pathogens.

Post-weaning diarrhea is responsible for major economic losses in the swine industry [83]. Enterotoxigenic E. coli (ETEC) is the major cause of this enteric disease in pigs, being responsible for approximately $50 \%$ of piglet mortality [83]. Al Atya et al. [84] showed that combining colistin with bacteriocins (nisin, enterocin) from lactic acid bacteria enhances its in vitro antibacterial activity against planktonic and biofilm cultures of $E$. coli. They suggested that colistin disrupts the outer membrane of $E$. coli by acting on lipopolysaccharide, opening the way for the subsequent action of the bacteriocins [84]. Colicins, a class of bacteriocins produced by and active against $E$. coli, have been investigated as a possible alternative to antibiotics in swine production [85]. Colicin E1 inhibits the growth of $E$. coli strains that cause post-weaning diarrhea and edema disease in pigs, as shown in vitro [86]. Furthermore, Cutler et al. [87] showed that the addition of colicin E1 to the diet of piglets decreases the incidence and severity of experimental post-weaning diarrhea induced by an enterotoxigenic strain of $E$. coli and improved the growth performance of piglets. They also used a gene expression analysis (IL- $\beta$, TNF- $\beta$ ) to show that the inflammatory response occurring in ileal tissues leading to diarrhea was decreased. These promising results indicate that the use of colicins may have a positive impact on food safety since enterotoxigenic $E$. coli is considered to be an important foodborne pathogen.

Haemophilus parasuis causes Glässer's disease in young pigs [88]. This systemic disease is characterized by polyserositis and fibrinopurulent polyarthritis. Teixeira et al. [89] reported the isolation of a low molecular mass bacteriocin from a reference strain of $B$. subtilis subsp. spizezinii (ATCC 6633). The bacteriocin was highly effective against approximately half the $H$. parasuis strains tested and may be a potential alternative to antibiotics for controlling infections caused by this pathogen.

Streptococcus suis, a common inhabitant of the tonsils of healthy pigs, is a major swine pathogen that has been associated with severe infections such as meningitis, arthritis, endocarditis, pneumonia, and septicemia [90]. It is one of the main bacterial pathogens responsible for major economic losses in the swine industry worldwide. In addition, this Gram positive bacterium is recognized as an emerging zoonotic agent for humans exposed to sick pigs or their by-products and has caused major outbreaks in Asia [91]. The nisin-producing strain L. lactis subsp. lactis ATCC 11404 exerts antagonistic activity toward S. suis, suggesting that this bacterial species may represent a probiotic of interest for the control of S. suis infections [92]. Moreover, all the S. suis isolates tested were susceptible to purified nisin, with MIC values ranging from 1.25 to $5 \mu \mathrm{g} / \mathrm{mL}$ [92]. When nisin was combined with conventional antibiotics such as amoxicillin and ceftiofur, which are commonly used to treat S. suis infections, strong synergistic effects were obtained [92]. These in vitro results provide support for the potential of nisin, a lantibiotic licensed as a food preservative, for preventing swine infections caused by S. suis. The purification 
and characterization of three lantibiotics, named suicins $90-1330,3908$, and 65 , produced by three distinct strains of S. suis (serotype 2) have recently been reported [93-95]. Interestingly, all three producing strains were non-virulent in mouse/pig infection models, and two of them were isolated from healthy carrier pigs [93-95]. The distribution of suicin gene clusters in S. suis serotype 2 belonging to sequence type (ST) 25 and ST28, the two dominant STs in North America, was recently investigated [96]. The gene clusters encoding suicin 65 (mostly in ST25 strains) and, to a lesser extent, suicin 90-1330 (exclusively in ST28 strains) are the most prevalent. Since all three suicins are bactericidal for highly virulent ST1 $S$. suis strains, which are mainly found in Eurasia, the use of the semi-purified bacteriocin preparations or the bacteriocin-producing strain may represent a valuable strategy for controlling S. suis infections and for reducing antibiotic use in the swine industry.

In 2012, Riboulet-Bisson et al. [97] evaluated the impact of Lactobacillus salivarius administration and, more specifically, the effect of bacteriocin production by this bacterium on the intestinal microbiota of healthy pigs. $L$. salivarius strain UCC118 is a well-known probiotic bacterium of human origin that produces a broad-spectrum class IIb bacteriocin [98]. Administering the bacteriocinproducing $L$. salivarius resulted in the modulation of the Gram-negative bacterial population of the intestinal microflora, decreasing the levels of Bacteroidetes and Spirochaetes [97]. Such an effect was not observed with a mutant lacking bacteriocin production. Although members of these two phyla are mostly commensals, under certain conditions they may become opportunistic pathogens in humans and animals. For example, Treponema spp. and Bacteroides spp. can cause colitis [99] and diarrhea [100], respectively.

Pediocin is a broad-spectrum class IIa bacteriocin produced by $P$. pentosaceus [101]. Casadei et al. [102] investigated the in vitro effects of pediocin $\mathrm{A}$, on microbial metabolism in the small and large intestines of pigs. While pediocin A had no effect on the fermentation parameters of the small intestine, it significantly reduced the growth of harmful bacteria, including clostridia and coliforms, and increased the metabolic activity of cellulolytic bacteria [102]. Based on these observations, the authors suggested that pediocin A could be an alternative to replace AGP and to improve the production of farm animals.

\subsection{Foodborne pathogens}

Poultry and poultry products (particularly eggs) are considered to be a major source of human infections, being responsible for approximately $50 \%$ of foodborne disease outbreaks [103]. The use of bacteriocins and bacteriocin-producing bacteria may be a viable strategy for reducing the colonization of the gastrointestinal tract of poultry by foodborne pathogens, including Campylobacter jejuni and Salmonella enterica. The prevalence of Campylobacter colonization, particularly of C. jejuni, in broiler flocks is highly variable but can reach $60-80 \%$ of flocks of slaughter age in Europe and the United States [104]. While C. jejuni is not considered to be a poultry pathogen, it is a foodborne and human pathogen of primary importance [105]. C. jejuni infections in humans are a leading cause of diarrheal disease and foodborne gastroenteritis worldwide [105]. C. jejuni infections (campylobacteriosis) are mostly associated with the consumption of undercooked poultry products [106]. The use of bacteriocins active against $C$. jejuni may be a promising strategy to improve food safety and protect public health [107, 108]. Over the past ten years, several studies have reported that numerous bacterial species in poultry, including L. salivarius [109, 110], Bacillus circulans [111] Paenibacillus polymyxa [111], Enterococcus faecium [112, 113], Carnobacterium divergens [114], Leuconostoc mesenteroides [115], and Lactobacillus sakei [116] produce bacteriocins that are active against C. jejuni. Interestingly, some of these bacteriocins possess desirable properties for in vivo applications, including heat and low $\mathrm{pH}$ tolerance, simple production and extraction processes, and no toxicity toward eukaryotic cells. The oral administration of semi-purified bacteriocins to effectively control foodborne pathogens can be easily achieved by incorporating them into feed or drinking water. Stern et al. [117] showed that incorporating purified bacteriocin B602 (secreted by P. polymyxa) encapsulated in polyvinylpyrrolidone in chicken feed significantly reduces the intestinal levels and the frequency of chicken colonization by C. jejuni. B602-supplemented feeds have also been shown to reduce Campylobacter colonization to undetectable levels in turkeys [118]. Bacteriocin OR-7, which is produced by a $L$. salivarius strain isolated from the cecum of a commercial broiler, also inhibits $C$. jejuni in vitro [119]. Polyvinylpyrrolidone-encapsulated bacteriocin OR-7 added to chicken feeds reduces $C$. jejuni colonization at least one million-fold compared with control birds [119]. Line et al. [120] showed that enterocin E-760, which was isolated from Enterococcus sp. NRRL B-30745, reduces the colonization of naturally acquired Campylobacter species in market age broiler chickens when administered in feeds [120], More specifically, the administration of enterocin E-760 was associated with an impressive 8-log reduction in Campylobacter counts in broiler chickens [120].

Salmonella is a major foodborne pathogen responsible for more than a million illnesses annually in the 
United States alone due to the consumption of animal products: poultry, poultry products, meat and dairy [121]. The poultry industry has also investigated the use of bacteriocins and/or bacteriocin-producing bacteria for their ability to control Salmonella [122-124]. Several studies have indicated that such probiotics, either inoculated orally into chickens or incorporated into feed, inhibit the growth of enteric pathogens such as Salmonella, likely by competitive exclusion or by the production of antimicrobial metabolites [122-124]. The administration of bacteriocin-producing bacteria can have a direct effect on reducing existing populations of Salmonella, while long-term colonization with bacteriocin-producing bacteria may prevent the reintroduction of Salmonella [122]. The bacteriocin albusin B, which is produced by Ruminococcus albus 7, has been reported to increase intestinal nutrient absorption, elevate fecal Lactobacillus counts, and decrease Salmonella loads, thereby improving the growth performance of broiler chickens [78]. Van Winsen et al. showed that L. plantarum does not display antimicrobial activity against Salmonella, but its addition to swine feeds resulted in a competition phenomenon that inhibits Salmonella growth and allows $L$. plantarum to dominate the intestinal flora [125]. The administration of bacteriocin-producing bacteria rather than the bacteriocins themselves might be a more cost-effective approach, but significant progress in developing suitable producer strains will have to be made before such an approach becomes feasible.

\section{Conclusions}

As more countries develop antibiotic-limiting policies, the need for alternative antimicrobials will likely become the main driving force behind the identification of novel bacteriocins and the testing of existing ones. The use of semi-purified bacteriocins or bacteriocin-producing bacteria in animal production is a field with enormous research and commercialization potential. Bacteriocins hold great promise for the prevention and/or treatment of bacterial diseases and may eventually be employed as alternatives to antibiotics (Figure 1).

Bacteriocins not only represent alternatives to AGP but are also considered as promising therapeutic agents for animal disease prevention, control, and treatments. Several clinical and pre-clinical trials have explored the

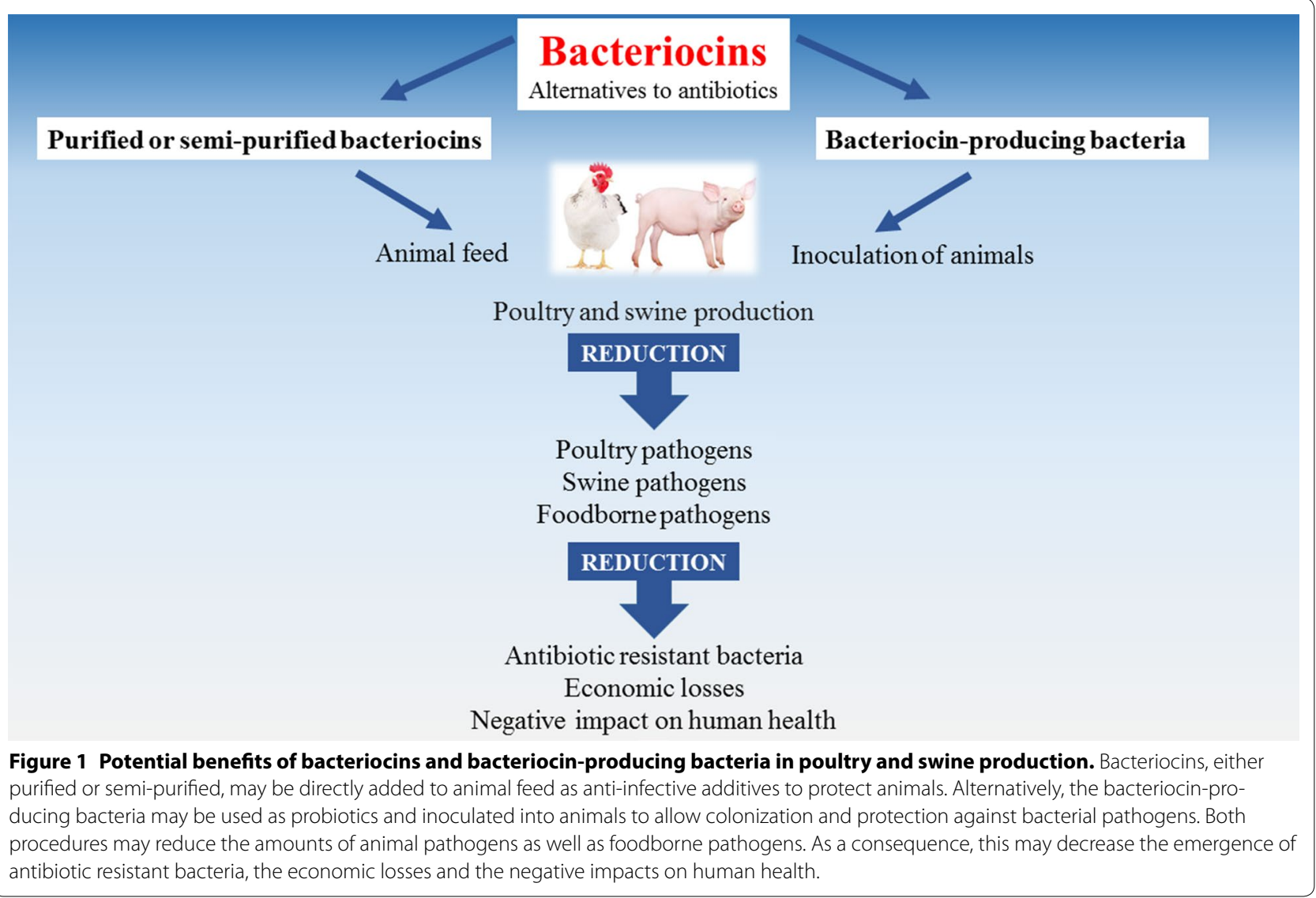


potential of purified bacteriocins as effective antimicrobial therapeutics or prophylactics and have given promising results $[81,118]$. A number of issues remain to be addressed, however, including the production cost, dosage, timing, and in vivo activity of each bacteriocin. Since bacteriocins can be digested in the gastrointestinal tract, the administration of bacteriocin-producing bacteria rather than the bacteriocins themselves may be a more effective approach. In fact, the use of bacteriocin producers as probiotics may be cost-effective, and could target specific pathogens without affecting beneficial bacteria. A combination of multiple strains producing different bacteriocins might more efficiently target pathogenic bacteria. However, several conditions must be met, including the successful colonization of the digestive tract by the bacteriocin-producing bacteria and the actual production of bacteriocins in this environment.

Bacteriocins can also be used to decrease the numbers of potentially pathogenic bacteria in waste water and manure in order to limit their transmission to humans. Lauková et al. [126] evaluated the effectiveness of bacteriocin CBE V24, which is produced by E. faecalis V24, in reducing the numbers of potential human pathogenic bacteria found in cattle dung water and manure. They suggested that bacteriocins such as CBE V24 could be used to better manage animal excrement and waste water without resorting to antibiotics [126]. These applications could be easily transferred to the poultry and swine industries. However, further research is required to confirm this possibility.

\section{Competing interests}

The authors declare that they have no competing interests.

\section{Authors' contributions}

The authors contributed equally to drafting the present review. All authors read and approved the final manuscript.

\section{Acknowledgements}

We wish to thank the Ministère de l'Agriculture, des Pêcheries et de I'Alimentation du Québec (MAPAQ) and the Natural Sciences and Engineering Research Council of Canada for supporting the bacteriocin studies performed in the author's laboratory.

\section{Author details}

${ }^{1}$ Groupe de Recherche en Écologie Buccale (GREB), Faculté de médecine dentaire, Université Laval, Quebec City, QC, Canada. ${ }^{2}$ Groupe de Recherche sur les Maladies Infectieuses du Porc (GREMIP), Faculté de médecine vétérinaire, Université de Montréal, Saint-Hyacinthe, QC, Canada. ${ }^{3}$ Centre de Recherche en Infectiologie Porcine et Avicole (CRIPA), Fonds de Recherche du QuébecNature et Technologies (FQRNT), Saint-Hyacinthe, QC, Canada.

\section{Publisher's Note}

Springer Nature remains neutral with regard to jurisdictional claims in published maps and institutional affiliations.

Received: 16 January 2017 Accepted: 21 March 2017

Published online: 11 April 2017
References

1. Love DC, Davis MF, Bassett A, Gunther A, Nachman KE (2011) Dose imprecision and resistance: free-choice medicated feeds in industrial food animal production in the United States. Environ Health Perspect 119:279-283

2. Maron DF, Smith TJ, Nachman KE (2013) Restrictions on antimicrobial use in food animal production: an international regulatory and economic survey. Global Health 9:48

3. US Food and Drug Administration (2014) FDA annual summary report on antimicrobials sold or distributed in 2012 for use in food-producing animals. http://www.fda.gov/AnimalVeterinary/NewsEvents/CVMUpdates/ucm416974.htm

4. van Rennings $L$, von Münchhausen $C$, Ottilie H, Hartmann M, Merle R, Honscha W, Käsbohrer A, Kreienbrock L (2015) Cross-sectional study on antibiotic usage in pigs in Germany. PLoS One 10:e0119114

5. European Medicines Agency (2016) Sales of veterinary antimicrobial agents in 29 European countries in 2014. Trends from 2011 to 2014. Report EMA/236501/2013. European Medicines Agency, London

6. Aarestrup FM, Oliver Duran C, Burch DG (2008) Antimicrobial resistance in swine production. Anim Health Res Rev 9:135-148

7. Teillant A, Laxminarayan R (2015) Economics of antibiotic use in US swine and poultry production. Choices 30:1-11

8. Allen HK, Levine UY, Looft T, Bandrick M, Casey TA (2013) Treatment, promotion, commotion: antibiotic alternatives in food-producing animals. Trends Microbiol 21:114-119

9. Miller GY, McNamara PE, Bush EJ (2003) Productivity and economic effects of antibiotics used for growth promotion in pork production. J Agric Appl Econ 35:469-482

10. Cromwell GL (2002) Why and how antibiotics are used in swine production. Anim Biotechnol 13:7-27

11. Emborg H, Ersboll AK, Heuer OE, Wegener HC (2001) The effect of discontinuing the use of antimicrobial growth promoters on the productivity in the Danish broiler production. Prev Vet Med 50:53-70

12. Teillant A (2015) Costs and benefits of antimicrobial use in livestock. AMR Control 2015:116-122

13. Davies J, Davies D (2010) Origins and evolution of antibiotic resistance. Microbiol Mol Biol Rev 74:417-433

14. Marshall BM, Levy SB (2011) Food animals and antimicrobials: impacts on human health. Clin Microbiol Rev 24:718-733

15. Barton MD (2014) Impact of antibiotic use in the swine industry. Curr Opin Microbiol 19:9-15

16. Huang SY, Zhu XQ, Wang Y, Liu HB, Dai L, He JK, Li BB, Wu CM, Shen JZ (2012) Co-carriage of qnrS1, floR, and bla $a_{\mathrm{CTX}-\mathrm{M}-14}$ on a multidrug-resistant plasmid in Escherichia coli isolated from pigs. Foodborne Pathog Dis 9:896-901

17. Morales AS, Fraqoso de Araujo J, de Moura Gomes VT, Reis Costa AT, dos Prazeres Rodrigues D, Porfida Ferreira TS, de Lima Filsner PH, Felizardo MR, Micke Moreno A (2012) Colistin resistance in Escherichia coli and Salmonella enterica strains isolated from swine in Brazil. Sci World J 2012:109795

18. Wasteson Y, Hoie S, Roberts MC (1994) Characterization of antibiotic resistance in Streptococcus suis. Vet Microbiol 41:41-49

19. Aarestrup FM, Rasmussen SR, Artursson K, Jensen NE (1998) Trends in the resistance to antimicrobial agents of Streptococcus suis isolates from Denmark and Sweden. Vet Microbiol 63:71-80

20. Wang Y, Li D, Song L, Liu Y, He T, Liu H, Wu C, Schwarz S, Shen J (2013) First report of the multiresistance gene cfr in Streptococcus suis. Antimicrob Agents Chemother 57:4061-4063

21. Karczmarczyk M, Abbott Y, Walsh C, Leonard N, Fanning S (2011) Characterization of multidrug-resistant Escherichia coli isolates from animals presenting at a university veterinary hospital. Appl Environ Microbiol 77:7104-7112

22. Akhtar F, Rabbani M, Muhammad K, Younus M, Ghafoor A, Sheikh AA, Ahmad A, Muhammad J, Rasool A, Shaheen AY (2016) Comparative antibiotic resistance profile of the multidrug resistant $E$. coli isolated from commercial and backyard poultry. J Anim Plant Sci 26:1628-1632

23. Diarra MS, Malouin F (2014) Antibiotics in Canadian poultry productions and anticipated alternatives. Front Microbiol 5:282

24. Da Costa PM, Loureiro L, Matos AJF (2013) Transfer of multidrug-resistant bacteria between intermingled ecological niches: the interface 
between humans, animals and the environment. Int J Environ Res Public Health 10:278-294

25. Nelson JM, Chiller TM, Powers JH, Angulo FJ (2007) Fluoroquinoloneresistant Campylobacter species and the withdrawal of fluoroquinolones from use in poultry: a public health success story. Clin Infect Dis 44:977-980

26. World Health Organization global strategy for containment of antimicrobial resistance. http://www.who.int/drugresistance/WHO_Global_ Strategy_English.pdf. Accessed 20 Nov 2016

27. US Food and Drug Administration/Center for Veterinary Medicine takes significant steps to address antimicrobial resistance. https://wayback. archive-it.org/7993/20170111230147/, http://www.fda.gov/AnimalVeterinary/NewsEvents/CVMUpdates/ucm378166.htm. Accessed 20 Nov 2016

28. Aarestrup FM, Seyfarth AM, Emborg HD, Pedersen K, Hendriksen RS, Bager $F$ (2001) Effect of abolishment of the use of antimicrobial agents for growth promotion on occurrence of antimicrobial resistance in fecal enterococci from food animals in Denmark. Antimicrob Agents Chemother 45:2054-2059

29. World Health Organization (2000) Impacts of antimicrobial growth promoter termination in Denmark. The WHO international review panel's evaluation of the termination of the use of antimicrobial growth promoters in Denmark. Geneva, No:WHO/CDS/CPE/ZFK/2003.1

30. Price LB, Lackey LG, Vailes R, Silbergeld E (2007) The persistence of fluoroquinolone-resistant Campylobacter in poultry production. Environ Health Perspect 115:1035-1039

31. Hammerum A, Heuer O (2009) Human health hazards from antimicrobial-resistant Escherichia coli of animal origin. Clin Infect Dis 48:916-921

32. Gratia A (1925) Sur un remarquable exemple d'antagonisme entre deux souches de colibacille. CR Soc Biol 93:1040-1042

33. Hammami R, Zouhir A, Le Lay C, Ben Hamida J, Fliss I (2010) BACTIBASE second release: a database and tool platform for bacteriocin characterization. BMC Microbiol 10:22

34. Riley MA, Wertz JE (2002) Bacteriocins: evolution, ecology, and application. Ann Rev Microbiol 56:117-137

35. Bastos Mdo C, Coelho ML, Santos OC (2015) Resistance to bacteriocins produced by Gram positive bacteria. Microbiology 161:683-700

36. Cavera VL, Arthur TD, Kashtanov D, Chikindas ML (2015) Bacteriocins and their position in the next wave of conventional antibiotics. Int J Antimicrob Agents 46:494-501

37. Wolska Kl, Grzes K, Kurek A (2012) Synergy between antimicrobials and conventional antibiotics or bacteriocins. Pol J Microbiol 61:95-104

38. Torres NI, Noll KS, Xu S, Li J, Huang Q, Sinko PJ, Wachsman MB, Chikindas ML (2013) Safety, formulation, and in vitro antiviral activity of the antimicrobial peptide subtilosin against herpes simplex virus type 1. Probiotics Antimicrob Proteins 5:26-35

39. Todorov SD, Wachsman M, Tomé E, Dousset X, Destro MT, Dicks LM, Franco BD, Vaz-Velho M, Drider D (2010) Characterisation of an antiviral pediocin-like bacteriocin produced by Enterococcus faecium. Food Microbiol 27:869-879

40. Cotter PD, Ross RP, Hill C (2013) Bacteriocins-a viable alternative to antibiotics? Nat Rev Microbiol 11:95-105

41. Hiron A, Falord M, Valle J, Débarbouillé M, MsadekT (2011) Bacitracin and nisin resistance in Staphylococcus aureus: a novel pathway involving the BraS/BraR two-component system (SA2417/SA2418) and both the $\mathrm{BraD} / \mathrm{BraE}$ and VraD/NraE ABC transporters. Mol Microbiol 81:602-622

42. Gravesen A, Ramnath M, Rechinger KB, Andersen N, Jänsch L, Héchard Y, Hastings JW, Knøchel S (2002) High-level resistance to class lla bacteriocins is associated with one general mechanism in Listeria monocytogenes. Microbiology 148:2361-2369

43. Kjos M, Nes IF, Diep DB (2011) Mechanisms of resistance to bacteriocins targeting the mannose phosphotransferase system. Appl Environ Microbiol 77:3335-3342

44. Cotter PD, Hill C, Ross RP (2005) Bacteriocins: developing innate immunity for food. Nat Rev Microbiol 3:777-788

45. Heng NCK, Tagg JR (2006) What's in a name? Class distinction for bacteriocins. Nat Rev Microbiol. doi:10.1038/nrmicro1273-c1

46. Bierbaum G, Sahl HG (2009) Lantibiotics: mode of action, biosynthesis and bioengineering. Curr Pharm Biotechnol 10:2-18

47. Balciunas EM, Martinez FAC, Todorov SD, de Melo Gombossy, Franco BD, Converti A, de Souza Oliveira RP (2013) Novel biotechnological applications of bacteriocins: a review. Food Control 32:134-142
48. Alvarez-Sieiro P, Montalban-Lopez M, Mu D, Kuipers OP (2016) Bacteriocins of lactic acid bacteria: extending the family. Appl Microbiol Biotechnol 100:2939-2951

49. Gabrielsen C, Brede DA, Nes IF, Diep DB (2014) Circular bacteriocins: biosynthesis and mode of action. Appl Environ Microbiol 80:6854-6862

50. Van Belkum MJ, Martin-Visscher LA, Vaderas JC (2011) Structure and genetics of circular bacteriocins. Trends Microbiol 19:411-418

51. Galvez A, Abriouel H, Lopez RL, Ben Omar N (2007) Bacteriocin-based strategies for food biopreservation. Int J Food Microbiol 120:51-70

52. Twomey D, Ross RP, Ryan M, Meany B, Hill C (2002) Lantibiotics produced by lactic acid bacteria: structure, function and applications. Antonie Van Leeuwenhoek 82:165-185

53. US Food and Drug Administration (1988) Nisin preparation: affirmation of GRAS status as direct human food ingredient. Fed Reg 53:11247-11251

54. Gharsallaoui A, Oulahal N, Joly C (2016) Nisin as a food preservative: part 1: Physicochemical properties, antimicrobial activity and main uses. Crit Rev Food Sci Nutr 56:1262-1274

55. Shin JM, Gwak JW, Kamarajan P, Fenno JC, Rickard AH, Kapila YL (2016) Biomedical applications of nisin. J Appl Microbiol 120:1449-1465

56. Cao LT, Wu JQ, Xie F, Hu SH, Mo Y (2007) Efficacy of nisin in treatment of clinical mastitis in lactating dairy cows. J Dairy Sci 90:3980-3985

57. Halasa T, Huijps K, Osteras O, Hogeveen H (2007) Economic effects of bovine mastitis and mastitis management: a review. Vet $\mathrm{Q}$ 29:18-31

58. Drider D, Bendali F, Naghmouchi K, Chikindas ML (2016) Bacteriocins: not only antibacterial agents. Probiotics Antimicrob Prot 8:177-182

59. De Kwaadsteniet M, Doeschate KT, Dicks LM (2008) Nisin F in the treatment of respiratory tract infections caused by Staphylococcus aureus. Lett Appl Microbiol 48:65-70

60. Kruszewska D, Sahl HG, Bierbaum G, Pag U, Hynes SO, Ljungh A (2004) Mersacidin eradicates methicillin-resistant Staphylococcus aureus (MRSA) in a mouse rhinitis model. J Antimicrob Chemother 54:648-653

61. Piper C, Casey PG, Hill C, Cotter PD, Ross RP (2012) The lantibiotic lacticin 3147 prevents systemic spread of Staphylococcus aureus in a murine infection model. Int J Microbiol 2012:806230

62. Belguesmia Y, Madi A, Sperandio D, Merieau A, Feuilloley M, Prévost H, Drider D, Connil N (2011) Growing insights into the safety of bacteriocins: the case of enterococcin S37. Res Microbiol 162:159-163

63. Chopra L, Singh G, Kumar Jena K, Sahoo DK (2015) Sonorensin: a new bacteriocin with potential of an anti-biofilm agent and a food biopreservative. Sci Rep 5:13412

64. Kaur S, Kaur S (2015) Bacteriocins as potential anticancer agents. Front Pharmacol 10:272

65. Pattison M, McMullin PF, Bradbury JM, Alexander DJ (2008) Poultry diseases, 6th edn. Saunders Elsevier, Philadelphia

66. Timbermont L, Haesebrouck F, Ducatelle R, Van Immerseel F (2011) Necrotic enteritis in broilers: an updated review on the pathogenesis. Avian Pathol 40:341-347

67. Timbermont $L$, De Smet $L$, van Nieuwerburgh Parreira VR, van Driessche G, Haesebrouck F, Ducatelle R, Prescott J, Deforce D, Devreese B, van Immerseel F (2014) Perfrin, a novel bacteriocin associated with netB positive Clostridium perfringens strains from broilers with necrotic enteritis. Vet Res 45:40

68. Han SK, Shin MS, Park HE, Kim SY, Lee WK (2014) Screening of bacteriocinproducing Enterococcus faecalis strains for antagonistic activities against Clostridium perfringens. Korean J Food Sci Anim Resour 34:614-621

69. Bizani D, Brandelli A (2002) Characterization of a bacteriocin produced by a newly isolated Bacillus sp. strain 8 A. J Appl Microbiol 93:512-519

70. Klose V, Bayer K, Bruckbeck R, Schatzmayr G, Loibner AP (2010) In vitro antagonistic activities of animal intestinal strains against swine-associated pathogens. Vet Microbiol 144:515-521

71. Teo AY, Tan HM (2005) Inhibition of Clostridium perfringens by a novel strain of Bacillus subtilis isolated from the gastrointestinal tracts of healthy chickens. Appl Environ Microbiol 71:4185-4190

72. Barbosa TM, Serra CR, La Ragione RM, Woodward MJ, Henriques AO (2005) Screening for Bacillus isolates in the broiler gastrointestinal tract. Appl Environ Microbiol 71:968-978

73. Jayaraman S, Thangavel G, Kurian H, Mani R, Mukkalil R, Chirakkal H (2013) Bacillus subtilis PB6 improves intestinal health of broiler chickens challenged with Clostridium perfringens-induced necrotic enteritis. Poult Sci 92:370-374 
74. Grilli E, Messina MR, Catelli E, Morlacchini M, Piva A (2009) Pediocin A improves growth performance of broilers challenged with Clostridium perfringens. Poult Sci 88:2152-2158

75. Udompijitkul P, Paredes-Sabja D, Sarker MR (2012) Inhibitory effects of nisin against Clostridium perfringens food poisoning and nonfoodborne isolates. J Food Sci 77:51-56

76. Jozefiak D, Kieronczyk B, Juskiewicz J, Zdunczyk Z, Rawski M, Dlugosz J, Sip A, Hojberg O (2013) Dietary nisin modulates the gastrointestinal microbial ecology and enhances growth performance of the broiler chickens. PLoS One 8:e85347

77. Jozefiak D, Sip A, Rawski M, Rutkowski A, Kaczmarek S, Hojberg O, Jensen BB, Engberg RM (2011) Dietary divercin modifies gastrointestinal microbiota and improves growth performance in broiler chickens. $\mathrm{Br}$ Poult Sci 52:492-499

78. Wang HT, Yu C, Hsieh YH, Chen SW, Chen BJ, Chen CY (2011) Effects of albusin B (a bacteriocin) of Ruminococcus albus 7 expressed by yeast on growth performance and intestinal absorption of broiler chickens - its potential role as an alternative to feed antibiotics. J Sci Food Agric 91:2338-2343

79. Dziva F, Stevens MP (2008) Colibacillosis in poultry: unravelling the molecular basis of virulence of avian pathogenic Escherichia coli in their natural hosts. Avian Pathol 37:355-366

80. Torshizi MAK, Rahimi S, Mojgani N, Esmaeilkhanian S, Grimes JL (2008) Screening of indigenous strains of lactic acid bacteria for development of a probiotic for poultry. Asian-Aust J Anim Sci 21:1495-1500

81. Ogunbanwo ST, Sanni Al, Onilude AA (2004) Influence of bacteriocin in the control of Escherichia coli infection of broiler chickens in Nigeria. World J Microbiol Biotechnol 20:51-56

82. Meat Atlas (2014) Facts and figures about the animals we eat. Heinrich Böll Foundation, Friends of the Earth Europe, Berlin

83. Fairbrother JM, Nadeau E, Gyles CL (2005) Escherichia coli in postweaning diarrhea in pigs: an update on bacterial types, pathogenesis, and prevention strategies. Anim Health Res Rev 6:17-39

84. Al Atya AK, Abriouel H, Kempf I, Jouy E, Auclair E, Vachée A, Drider D (2016) Effects of colistin and bacteriocins combinations on the in vitro growth of Escherichia coli strains from swine origins. Probiotics Antimicrob Proteins 8:183-190

85. Gillor O, Kirkup BC, Riley MA (2004) Colicins and microcins: the next generation of antimicrobials. Adv Appl Microbiol 54:129-146

86. Stahl CH, Callaway TR, Lincoln LM, Lonergan SM, Genovese KJ (2004) Inhibitory activities of colicins against Escherichia coli strains responsible for postweaning diarrhea and edema disease in swine. Antimicrob Agents Chemother 48:3119-3121

87. Cutler SA, Lonergan SM, Cornick N, Johnson AK, Stahl CH (2007) Dietary inclusion of colicin e1 is effective in preventing postweaning diarrhea caused by F18-positive Escherichia coli in pigs. Antimicrob Agents Chemother 51:3830-3835

88. Zhang B, Tang C, Liao M, Yue H (2014) Update on the pathogenesis of Haemophilus parasuis infection and virulence factors. Vet Microbiol 168:1-7

89. Teixeira ML, Dalla Rosa A, Brandelli A (2013) Characterization of an antimicrobial peptide produced by Bacillus subtilis subsp. spizezini showing inhibitory activity towards Haemophilus parasuis. Microbiology 159:980-988

90. Gottschalk M (2012) Streptococcosis, in Diseases of swine. In: Karriger L, Schwartz KJ, Stevenson G, Zimmerman J (eds). Wiley Publishers, New York, p 841-855

91. GottschalkM, Xu J,Calzas C, Segura M (2010) Streptococcus suis: a new emerging or an old neglected zoonotic pathogen? Future Microbiol 5:371-391

92. LeBel G, Piché F, Frenette M, Gottschalk M, Grenier D (2013) Antimicrobial activity of nisin against the swine pathogen Streptococcus suis and its synergistic interaction with antibiotics. Peptides 50:19-23

93. LeBel G, Vaillancourt K, Frenette M, Gottschalk M, Grenier D (2014) Suicin 90-1330 from a nonvirulent strain of Streptococcus suis: a nisinrelated lantibiotic active on gram-positive swine pathogens. Appl Environ Microbiol 80:5484-5492

94. Vaillancourt K, LeBel G, Frenette M, Gottschalk M, Grenier D (2015) Suicin 3908, a new lantibiotic produced by a strain of Streptococcus suis serotype 2 isolated from a healthy carrier pig. PLoS One 10:e0117245

95. Vaillancourt K, LeBel G, Frenette M, Fittipaldi N, Gottschalk M, Grenier D (2015) Purification and characterization of suicin 65 , a novel class I type B lantibiotic produced by Streptococcus suis. PLoS One 10:e0145854
96. Athey T, Vaillancourt K, Frenette M, Fittipaldi N, Gottschalk M, Grenier D (2016) Distribution of suicin gene clusters in Streptococcus suis serotype 2 belonging to sequence types 25 and 28. Biomed Res 2016:6815894

97. Riboulet-Bisson E, Sturme MH, Jeffery IB, O'Donnell MM, Neville BA, Forde BM, Claesson MJ, Harris H, Gardiner GE, Casey PG, Lawlor PG, O'Toole PW, Ross RP (2012) Effect of Lactobacillus salivarius bacteriocin Abp1 18 on the mouse and pig intestinal microbiota. PLoS One 7:e31113

98. Corr SC, LiY, Riedel CU, O’Toole PW, Hill C, Gahan CG (2007) Bacteriocin production as a mechanism for the antiinfective activity of Lactobacillus salivarius UCC118. Proc Natl Acad Sci USA 104:7617-7621

99. Mølbak L, Klitgaard K, Jensen TK, Fossi M, Boye M (2006) Identification of a novel, invasive, not-yet-cultivated Treponema sp. in the large intestine of pigs by PCR amplification of the 16S rRNA gene. J Clin Microbiol 44:4537-4540

100. W.ick EC, Sears CL (2010) Bacteroides spp. and diarrhea. Curr Opin Infect Dis 23:470-474

101. Rodríguez JM, Kok J (2002) Pediocin PA-1, a wide-spectrum bacteriocin from lactic bacteria. Crit Rev Food Sci Nutr 42:91-121

102. Casadei G, Grilli E, Piva A (2009) Pediocin A modulates intestinal microflora metabolism in swine in vitro intestinal fermentations. J Anim Sci 87:2020-2028

103. Mor-Mur M, Yuste J (2010) Emerging bacterial pathogens in meat and poultry: an overview. Food Bioprocess Tech 3:24-35

104. Hermans D, Van Deun K, Messens W, Martel A, Van Immerseel F, Haesebrouck F, Rasschaert G, Heyndrickx M, Pasmans F (2011) Campylobacter control in poultry by current intervention measures ineffective: urgent need for intensified fundamental research. Vet Microbiol 152:219-228

105. Humphrey T, O'Brien S, Madsen M (2007) Campylobacters as zoonotic pathogens: a food production perspective. Int J Food Microbiol $117: 237-257$

106. Allos BM (2001) Campylobacter jejuni infections: update on emerging issues and trends. Clin Infect Dis 32:1201-1206

107. Lin J (2009) Novel approaches for Campylobacter control in poultry. Foodborne Pathog Dis 6:755-765

108. Svetoch EA, Stern NJ (2010) Bacteriocins to control Campylobacter spp. in poultry-a review. Poult Sci 89:1763-1768

109. Svetoch EA, Eruslanov BV, Levchuk VP, Perelygin VV, Mitsevich EV, Mitsevich IP, Stepanshin J, Dyatlov I, Seal BS, Stern NJ (2011) Isolation of Lactobacillus salivarius 1077 (NRRL B-50053) and characterization of its bacteriocin, including the antimicrobial activity spectrum. Appl Environ Microbiol 77:2749-2754

110. Messaoudi S, Kergourlay G, Dalgalarrondo M, Choiset Y, Ferchichi M, Prévost H, Pilet MF, Chobert JM, Manai M, Dousset X (2012) Purification and characterization of a new bacteriocin active against Campylobacter produced by Lactobacillus salivarius SMXD51. Food Microbiol 32:129-134

111. Svetoch EA, Stern NJ, Eruslanov BV, Kovalev YN, Volodina LI, Perelygin V, Mitsevich EV, Mitsevich IP, Pokhilenko VD, Borzenkov VN, Levchuk VP, Svetoch OE, Kudriavtseva TY (2005) Isolation of Bacillus circulans and Paenibacillus polymyxa strains inhibitory to Campylobacter jejuni and characterization of associated bacteriocins. J Food Prot 68:11-17

112. Svetoch EA, Eruslanov BV, Perelygin WV, Mitsevich EV, Mitsevich IP, Borzenkov VN, Levchuk VP, Svetoch OE, Kovalev YN, Stepanshin YG, Siragusa GR, Seal BS, Stern NJ (2008) Diverse antimicrobial killing by Enterococcus faecium E 50-52 bacteriocin. J Agric Food Chem 56:1942-1948

113. Cintas LM, Casaus P, Herranz C, Hâvarstein LS, Holo H, Hernández PE, Nes IF (1997) Biochemical and genetic characterization of enterocin $P$, a novel sec-dependent bacteriocin from Enterococcus faecium P13 with a broad antimicrobial spectrum. Appl Environ Microbiol 63:4321-4330

114. Metivier A, Pilet MF, Dousset $X$, Sorokine $O$, Anglade P, Zagorec M, Piard JC, Marion D, Cenatiempo Y, Fremaux C (1998) Divercin V41, a new bacteriocin with two disulphide bonds produced by Carnobacterium divergens $\mathrm{V} 41$ : primary structure and genomic organization. Microbiology 144:2837-2844

115. Fleury Y, Dayem MA, Montagne JJ, Chaboisseau E, Le Caer JP, Nicolas P, Delfour A (1996) Covalent structure, synthesis, and structure-function studies of mesentericin Y 105(37), a defensive peptide from gram-positive bacteria Leuconostoc mesenteroides. J Biol Chem 271:14421-14429

116. Holck AL, Axelsson L, Huhne K, Krockel L (1994) Purification and cloning of sakacin 674, a bacteriocin from Lactobacillus sakei Lb674. FEMS Microbiol Lett 115:143-149 
117. Stern NJ, Svetoch EA, Eruslanov BV, Kovalev YN, Volodina LI, Perelygin W, Mitsevich EV, Mitsevich IP, Levchuk VP (2005) Paenibacillus polymyxa purified bacteriocin to control Campylobacter jejuni in chickens. J Food Prot 68:1450-1453

118. Cole K, Farnell MB, Donoghue AM, Stern NJ, Svetoch EA, Eruslanov BN, Volodina LI, Kovalev YN, Perelygin WV, Mitsevich EV, Mitsevich IP, Levchuk VP, Pokhilenko VD, Borzenkov VN, Svetoch OE, Kudryavtseva TY, Reyes-Herrera I, Blore PJ, Solis de los Santos F, Donoghue DJ, (2006) Bacteriocins reduce Campylobacter colonization and alter gut morphology in turkey poults. Poult Sci 85:1570-1575

119. Stern NJ, Svetoch EA, Eruslanov BV, Perelygin WV, Mitsevich EV, Mitsevich IP, Pokhilenko VD, Levchuk VP, Svetoch OE, Seal BS (2006) Isolation of a Lactobacillus salivarius strain and purification of its bacteriocin, which is inhibitory to Campylobacter jejuni in the chicken gastrointestinal system. Antimicrob Agents Chemother 50:3111-3116

120. Line JE, Svetoch EA, Eruslanov BV, Perelygin VV, Mitsevich EV, Mitsevich IP, Levchuk VP, Svetoch OE, Seal BS, Siragusa GR, Stern NJ (2008) Isolation and purification of enterocin E-760 with broad antimicrobial activity against gram-positive and gram-negative bacteria. Antimicrob Agents Chemother 52:1094-1100
121. Scallan E, Hoekstra RM, Angulo FJ, Tauxe RV, Widdowson MA, Roy SL, Jones JL, Griffin PM (2011) Foodborne illness acquired in the United States - major pathogens. Emerg Infect Dis 17:7-15

122. Diez-Gonzalez F (2007) Applications of bacteriocins in livestock. Curr Issues Intest Microbiol 8:15-23

123. Joerger RD (2003) Alternatives to antibiotics: bacteriocins, antimicrobial peptides and bacteriophages. Poult Sci 82:640-647

124. Vandeplas S, Dubois Dauphin R, Beckers Y, Thonart P, Théwis A (2010) Salmonella in chicken: current and developing strategies to reduce contamination at farm level. J Food Prot 73:774-785

125. Van Winsen RL, Lipman LJA, Biesterveld S, Urlings BAP, Snijders JMA, van Knapen $F$ (2001) Mechanisms of Salmonella reduction in fermented pig feed. J Sci Food Agric 81:342-346

126. Laukova A, Juris P, Vasilková Z, Papajová I (2000) Treatment of sanitaryimportant bacteria by bacteriocin substance V24 in cattle dung water. Lett Appl Microbiol 30:402-405

\section{Submit your next manuscript to BioMed Central and we will help you at every step:}

- We accept pre-submission inquiries

- Our selector tool helps you to find the most relevant journal

- We provide round the clock customer support

- Convenient online submission

- Thorough peer review

- Inclusion in PubMed and all major indexing services

- Maximum visibility for your research

Submit your manuscript at www.biomedcentral com/submit
() Biomed Central 